\title{
Cross infection in a surgical ward caused by Pseudomonas aeruginosa with transferable resistance to gentamicin and tobramycin
}

\author{
F. R. FALKINER, C. T. KEANE, M. DALTON, ${ }^{1}$ M. T. CLANCY, AND G. A. JACOBY
}

From the Central Microbiology Laboratory, Adelaide Hospital, Dublin 8, and the Massachusetts General Hospital, Boston, Massachusetts 02114, USA

SUMMARY An outbreak of gentamicin- and tobramycin-resistant Pseudomonas aeruginosa infection occurred in a surgical ward over a three-month period. Resistant Ps. aeruginosa strains with the same serological, phage, and pyocin type were cultured from the urine of six patients. Identical organisms were found on urine bottles, bedpans, and the hands of attendant staff. Inadequate disinfection played a major role in cross-infection. Isolates of the epidemic strain from each of the patients and of an unrelated but similarly resistant Ps. aeruginosa from one of them could transfer resistance to a recipient strain of Ps. aeruginosa. Resistance to gentamicin, kanamycin, tobramycin, sulphonamides, and mercuric chloride was determined by $\mathbf{R}$ factors belonging to Pseudomonas incompatibility group P-3. Aminoglycoside resistance was due to acetylation.

Urinary tract infection is the commonest type of hospital-acquired infection and is particularly associated with catheter drainage. Micro-organisms may enter through the lumen of the catheter or between the catheter and the wall of the urethra. Pseudomonas aeruginosa is a common aetiological agent, and owing to its pronounced resistance to antimicrobials the choice of an appropriate drug is limited. Gentamicin has a valuable place in therapy; the emergence of resistant strains is therefore important. Isolated reports of gentamicin-resistant strains of Ps. aeruginosa have been documented in the United Kingdom with no evidence of linked cases (Barnham et al., 1975; Eykyn and Phillips, 1975; Seal and Strangeways, 1975).

We report here a cross-infection of six patients with a strain of gentamicin- and tobramycinresistant $\boldsymbol{P s}$. aeruginosa. All isolates were from urine specimens. Some of the patients had significant bacteriuria. The resistance was transferable to another strain of Ps. aeruginosa. The properties of the $\mathbf{R}$ plasmids involved were different from those previously isolated from $P s$. aeruginosa in the United Kingdom.

1Present address: Department of Microbiology, St Thomas's Hospital Medical School, London SE1 7EH

Received for publication 2 February 1977

\section{Patients}

The outbreak occurred in a surgical ward. Six patients were affected from February to April 1975.

\section{CASE 1}

A 79-year-old man with benign hyperplasia of the prostate, admitted from another hospital on catheter drainage at the beginning of February 1975, had a urinary tract infection and septicaemia with a susceptible Escherichia coli which responded to gentamicin. Three weeks later he had a transurethral resection and was catheterised. After three days the catheter was removed and he was treated with cotrimoxazole blindly. A specimen of urine showed pyuria and significant ( $>100000$ organisms $/ \mathrm{ml}$ ) bacteriuria with a strain of $P$ s. aeruginosa resistant to gentamicin, tobramycin, and carbenicillin (the epidemic strain). Two further specimens at 10-day intervals yielded the same strain. Treatment was with nalidixic acid, to which the strain was resistant. The patient's condition improved, and he was discharged apparently well.

\section{CASE 2}

An 86-year-old woman had a partial resection of the bladder for a transitional cell carcinoma in 1971 for which cobalt therapy was given. She was admitted 
in February 1975 for massive haematuria. After cystoscopy under anaesthetic and bladder washout she was catheterised. Ten days later the catheter was removed. A sample of urine showed pyuria and significant bacteriuria with $E$. coli. In a subsequent specimen the culture showed $E$. coli and the epidemic strain of $\boldsymbol{P}$ s. aeruginosa in significant numbers. A further specimen, however, showed a pure growth of $E$. coli. No specific antimicrobial therapy was given. She was transferred to another hospital for cobalt therapy.

\section{CASE 3}

A 53-year-old man had an adenocarcinoma of the prostate treated by orchidectomy and hormone and deep $x$-ray therapy in 1972 . A left pyeloplasty was performed and drainage established with a ureteric catheter in November 1974. In January 1975 pus was draining from the nephrostomy tube, so he was admitted to hospital and treated with co-trimoxazole empirically. Early in March the epidemic strain of $P$ s. aeruginosa was isolated from a ureteric specimen of urine. Two further specimens yielded the same strain. He was in severe renal failure and died shortly afterwards.

\section{CASE 4}

A 56-year-old woman with a history of renal calculi was admitted in March 1975 for investigation of bilateral ureteric strictures. After cytoscopy and right ureteric dilatation she was catheterised and given co-trimoxazole prophylactically. Dilatation of the left ureter was performed. A specimen showed pyuria and significant bacteriuria with $E$. coli and the epidemic strain of Ps. aeruginosa. This was not treated. She was discharged apparently well.

\section{CASE 5}

An 81-year-old man had arteriosclerotic dementia, prostatism, and acute retention. He was catheterised on admission in April 1975. A specimen showed pyuria and significant bacteriuria with the epidemic strain of Ps. aeruginosa. No further specimens of urine were received, and he was discharged well without specific therapy.

\section{CASE 6}

A 57-year-old man was admitted with a history of malignant neoplasm of the bladder and calculi in the kidneys, bladder, and urethra. The calculi had been removed and he had had deep $x$-ray therapy. In April 1975 he was admitted with acute retention and catheterised. Three weeks later a specimen showed pyuria and significant bacteriuria with the epidemic strain of Ps. aeruginosa. His condition deteriorated and he died without specific therapy.

\section{Bacteriological investigations}

The strains were identified as $P$ s. aeruginosa by the criteria of Phillips (1969). Isolates from patients into the ward over the previous three months as well as듬 those obtained in the epidemiological investigation $\overline{\overline{\bar{s}}}$ were typed by serology and bacteriophage sensitivity $\widehat{\varnothing}$ at the Central Public Health Laboratory, Colindale, London (Shooter et al., 1966). Active pyocin typing ${ }^{\infty}$ (Govan and Gillies, 1969) was done in the Centralo Microbiology Laboratory, Adelaide Hospital, $\vec{\omega}$ Dublin.

In a bacteriological survey of the environment samples were taken from drinking-water jugs, taps, basins, sinks, baths, sluices, bedpans, urine bottles, 0 and a number of sites in sluice rooms and the ward ${ }^{\infty}$ kitchen. In-use dilutions and stock solutions of disinfectants were tested for concentration with a응 comparator and cultured after neutralisation with? tryptone soya broth. Cultures were made from the $\vec{\square}$ hands of attendant staff by a modification of the technique of Bruun et al. (1968). Faecal specimens of the same staff were incubated in acetamide broth $\stackrel{+}{-}$ and subcultured on to cetrimide agar (Brown and $\mathcal{V}$ Lowbury, 1965; Smith and Dayton, 1972).

Transmissibility of antibiotic resistance was tested by mating with PU21, an isoleucine-valine and leucine-requiring streptomycin-and rifampicin- $\bar{O}$ resistant derivative of the PAO line of Ps. aeruginosa (Jacoby, 1974a). The recipient was pregrown at $\stackrel{\AA}{\complement}$ $43^{\circ} \mathrm{C}$ in an attempt to overcome the deoxyribonucleic $\overrightarrow{\vec{F}}$ acid restriction system that operates in this organism $\frac{3}{3}$ (Holloway, 1965). $10^{8} \mathrm{cells} / \mathrm{ml}$ of potential donor and recipient were mixed, incubated for about 18 hours? at $37^{\circ} \mathrm{C}$, and spread on plates containing a selective concentration of gentamicin $(20 \mu \mathrm{g} / \mathrm{ml})$, sulpha- 0 diazine $(5 \mathrm{mg} / \mathrm{ml})$, or tobramycin $(10 \mu \mathrm{g} / \mathrm{ml})$ and $\frac{\sigma}{3}$ rifampicin $(100 \mu \mathrm{g} / \mathrm{ml})$ to which the clinical strains were sensitive for counterselection (Jacoby, 1974a). $\frac{\bigcirc}{3}$

Transconjugants were tested for resistance to antibiotics by agar dilution (Jacoby, 1974a), mercuric chloride, and ultraviolet light and for lysis by $\frac{D}{2}$ bacteriophages B3, B39, C5, E79, F116, G101, M6, ․ㅡ. and PB1, all of which propagate on R-PU21 N (Jacoby, 1974a). The ability to inhibit the fertility of plasmid RP1 was tested by constructing strains $N$ carrying RP1 and each of the new R plasmids. An $\mathrm{Fi}^{+}$(RP1) plasmid inhibits lysis by phages PRR1, PRD1, Pf3, PR3, and PR4 that normally propagateo on RP1-carrying strains (Stanisich, 1974; Jacoby, 1977). Transfer proficiency was determined by mating each PU21 $\left(\mathrm{R}^{+}\right)$derivative with PU1 (FP2 ${ }^{+}+\frac{7}{\circ}$ prototrophic) selecting for tobramycin-resistant $\frac{\vec{D}}{D}$ transconjugants. A Tra- plasmid is not self-trans- $\stackrel{\mathbb{Q}}{\mathbb{P}}$ missible. Tra ${ }^{+}$Pu21 (pMG7) was also mated for $\stackrel{\mathbb{Q}}{\varrho}$ 18 hours with $E$. coli $\mathrm{C}$ selecting for transfer for 
gentamicin, tobramycin, or sulphonamide resistance.

Compatibility was tested by constructing. strains carrying pMG7 and a second plasmid of known incompatibility specificity. The test plasmids and their Pseudomonas incompatibility groups were RP1 (P-1), R931 (P-2), Rip64 and R151 (P-3), R1162 (P-4), Rms163 (P-5), Rms149 (P-6), Rms148 (P-7), pRO271 (P-8), and R2 and R716 unclassified (Bryan et al., 1973; Bryan et al., 1974; Olsen and Hansen, 1976; Jacoby, 1977). Most crosses were performed with PU21 containing the test plasmid as donor and PAO303 (RP- arg-18) (Jacoby, 1974 a) containing pMG7 as recipient. Twenty transconjugants were tested on antibiotic media selective for each plasmid individually to determine their ability to coexist with pMG7 except for crosses with R151 and R64 where phage resistance was scored, since the antibiotic resistance markers of these plasmids overlap those of pMG7.

Aminoglycosideacetylating activity was determined by the phosphocellulose-paper binding assay with ${ }^{14} \mathrm{C}$-acetyl coenzyme A as substrate (Haas et al., 1976). Assays were performed by Barbara Hoffman and Julian Davies at the University of Wisconsin, Madison, Wisconsin, USA.

\section{Results}

Patients 1 and 3 appeared to have a genuine infection. The epidemic strain was isolated once from each of the remaining four patients. The absence of followup specimens coupled with the poor urine collecting technique (see below) made it difficult to assess the significance of the isolates in cases $2,4,5$, and 6 . The organisms were resistant by disc sensitivity testing to carbenicillin, kanamycin, gentamicin, tobramycin, and sulphonamides. Colonial morphologies of the isolates were identical in all six patients in their unusual gelatinous consistency. The colonies were small, round, and glistening after 24 hours but became wrinkled on further incubation. Serological, bacteriophage, and pyocin typing reactions of the isolates from the six cases were identical (Table 1). No cultures of this type or colonial morphology had been isolated from the ward in the previous four years. Another strain (No. 1996) with identical resistance properties but a different typing reaction was also isolated from case 3.

The epidemiological survey was extensive but the resistant Pseudomonas was isolated only from bedpans and urine bottles. The latter were 'disinfected' in a solution of Hycolin. The 'in-use' concentration of this disinfectant was maintained in the ward at between $0.5 \%$ and $1 \%$. No organisms were isolated from it. In error, however, this solution was further diluted by about 100-fold. Several isolates of Ps. aeruginosa were made from this diluted solution when in use. One isolation of $P s$. fluorescens was also obtained from a jar steeping in this solution. Probably some of the urine specimens had been collected in unsterile containers before dispatch to the laboratory.

A nurse was found to be a carrier of the epidemic strain, which was isolated from her faeces on two occasions 10 days apart. A positive culture was also made from her hands. Sensitive strains of Pseudomonas were isolated from the faeces of another nurse and doctor. Cultures were made from the hands of attendant staff. Seven of them gave positive isolations for E. coli. Klebsiella, Proteus, Pseudomonas, and Enterococcus.

Isolates from each of the six cases and from a contaminated urine bottle could transmit multiple antibiotic resistance to a recipient strain of $P s$. aeruginosa (Table 1). The frequency of transfer was only $10^{-7}$ to $10^{-8}$ per recipient. Transconjugants acquired resistance to gentamicin, kanamycin, tobramycin, and sulphonamides but not carbenicillin (Table 2). The non-epidemic strain No. 1996

Table 1 Properties of Ps. aeruginosa strains. All strains were resistant to gentamicin, kanamycin, tobramycin, and sulphonamides. Weak bacteriophage reactions indicated in parentheses

\begin{tabular}{|c|c|c|c|c|c|c|}
\hline \multirow[t]{2}{*}{ Strain No. } & \multirow[t]{2}{*}{ Source } & \multirow[t]{2}{*}{ Specimen } & \multicolumn{3}{|c|}{ Typing reaction } & \multirow{2}{*}{$\begin{array}{l}\text { Transmissibility of } \\
\text { resistance }\end{array}$} \\
\hline & & & Pyocin & Serological & Bacteriophage & \\
\hline $\begin{array}{l}1771 \\
1775 \\
1881 \\
1996 \\
1881 \\
1882 \\
1922 \\
1935 \\
1936 \\
1938\end{array}$ & $\begin{array}{l}\text { Case } 1 \\
\text { Case } 2 \\
\text { Case } 3 \\
\text { Case } 3 \\
\text { Case } 4 \\
\text { Case } 5 \\
\text { Case } 6 \\
\\
\text { Nurse C }\end{array}$ & $\begin{array}{l}\text { Urine } \\
\text { Urine } \\
\text { Urine } \\
\text { Urine } \\
\text { Urine } \\
\text { Urine } \\
\text { Urine } \\
\text { Bedpan } \\
\text { Urine bottle } \\
\text { Faeces }\end{array}$ & $\begin{array}{l}6 e \\
6 e \\
6 e \\
6 a \\
6 e \\
6 e \\
6 e \\
6 e \\
6 e \\
6 e\end{array}$ & $\begin{array}{l}6 \\
6 \\
6 \\
\text { AA/NT } \\
6 \\
6 \\
6 \\
6 \\
6 \\
6\end{array}$ & $\begin{array}{l}109.1214 \\
109.1214(7.44) \\
109.1214(7.44) \\
188 / 1(31) \\
109.1214(7) \\
109.1214(7) \\
109.1214(7) \\
109.1214(7) \\
109.1214(7) \\
109.1214(7.44)\end{array}$ & $\begin{array}{l}+ \\
+ \\
+ \\
+ \\
+ \\
+ \\
+ \\
\text { Not tested } \\
+ \\
\text { Not tested }\end{array}$ \\
\hline
\end{tabular}

AA $=$ autoagglutinable. $\quad$ NT $=$ non-typable 
Table 2 Properties of $R$ plasmids from resistant strains

\begin{tabular}{|c|c|c|c|c|c|c|c|c|}
\hline \multirow[t]{2}{*}{ Strain No. } & \multirow[t]{2}{*}{ Source } & \multirow[t]{2}{*}{ Plasmid } & \multicolumn{4}{|c|}{ Resistance phenotype } & \multirow[t]{2}{*}{$F i(R P l)$} & \multirow[t]{2}{*}{ Tra } \\
\hline & & & Antibiotic & $H g$ & $\boldsymbol{U} \boldsymbol{V}$ & Phage & & \\
\hline $\begin{array}{l}1771 \\
1775 \\
1811 \\
1996 \\
1881 \\
1882 \\
1922 \\
1936\end{array}$ & $\begin{array}{l}\text { Case } 1 \\
\text { Case } 2 \\
\text { Case } 3 \\
\text { Case } 3 \\
\text { Case } 4 \\
\text { Case } 5 \\
\text { Case } 6 \\
\text { Urine bottle }\end{array}$ & $\begin{array}{l}\text { pMG7 } \\
\text { pMG8 } \\
\text { pMG9 } \\
\text { pMG10 } \\
\text { pMG11 } \\
\text { pMG12 } \\
\text { pMG13 } \\
\text { pMG14 }\end{array}$ & $\begin{array}{l}\text { Gm Km Tm Su } \\
\text { Gm Km Tm Su } \\
\text { Gm Km Tm Su } \\
\text { Gm Km Tm Su } \\
\text { Gm Km Tm Su } \\
\text { Gm Km Tm Su } \\
\text { Gm Km Tm Su } \\
\text { Gm Km Tm Su }\end{array}$ & $\begin{array}{l}\mathbf{R} \\
\mathbf{R} \\
\mathbf{R} \\
\mathbf{R} \\
\mathbf{R} \\
\mathbf{R} \\
\mathbf{R} \\
\mathbf{R}\end{array}$ & $\begin{array}{l}\mathbf{R} \\
\mathbf{S} \\
\mathbf{S} \\
\mathbf{R} \\
\mathbf{S} \\
\mathbf{S} \\
\mathbf{S} \\
\mathbf{R}\end{array}$ & $\begin{array}{l}\text { B3 D3 F116 G101 } \\
\text { B3 D3 F116 G101 } \\
\text { B3 D3 F116 G101 } \\
\text { B3 D3 F116 G101 } \\
\text { B3 D3 F116 G101 } \\
\text { B3 D3 F116 G101 } \\
\text { B3 D3 F116 G101 } \\
\text { B3 D3 F116 G101 }\end{array}$ & $\begin{array}{l}+ \\
+ \\
+ \\
+ \\
+ \\
+ \\
+ \\
+\end{array}$ & $\begin{array}{l}+ \\
- \\
- \\
- \\
- \\
-\end{array}$ \\
\hline
\end{tabular}

$\mathrm{Gm}=$ gentamicin. $\mathrm{Km}=$ kanamycin. $\mathrm{Tm}=$ tobramycin. Su = sulphonamides. $\mathrm{Hg}=$ mercuric chloride. $\mathrm{UV}=$ ultraviolet light. Fi(RPI) $=$ fertility inhibition of plasmid RPI. Tra = mediating conjugation. $\mathbf{S}=$ susceptible. $\mathbf{R}=$ resistant.

transferred a similar plasmid. In addition to antibiotic resistance all the plasmids determined resistance to mercuric chloride and to the same subset of bacteriophages. The effect on phage propagation could be shown to be due to a new restriction and modification specificity introduced by the $R$ plasmids (data not shown). Transconjugants from three of the eight donors were also resistant to ultraviolet light. All the $\mathbf{R}$ factors inhibited the fertility of plasmid RP1. Plasmid pMG7 was transmissible from PU21 to other strains of Ps. aeruginosa at a frequency of $10^{-5}$ to $10^{-6}$ but not to $E$. coli. The other plasmids were non-conjugative (Tra-).

Compatibility testing showed that plasmid pMG7 could coexist stably with $\mathrm{R}$ plasmids belonging to Pseudomonas incompatibility groups $\mathrm{P}-1, \mathrm{P}-2, \mathrm{P}-4$, P-5, P-6, P-7, and P-8 and with unclassified plasmids R2 and R716. Marked entry exclusion occurred with plasmid R151 and other P-3 group plasmids. Plasmids pMG7 and R151 were unable to coexist in the same host (Table 3), indicating that pMG7 belongs to the P-3 incompatibility group. Traplasmids pMG8-14 gave similar incompatibility results.

By agar-dilution sensitivity testing all the plasmids from this outbreak gave enhanced resistance to gentamicin, kanamycin, sisomicin, and tobramycin. Data for pMG7 are shown in Table 4. Cell-free extracts of Pu1 (pMG7) were assayed for aminoglycoside inactivity enzymes. Aminoglycoside acetyltransferase activity was present. The spectrum of activity toward different substrates is shown in Table 5.

\section{Discussion}

Lapses in aseptic routine contributed to this outbreak of resistant Ps. aeruginosa. All the patients had been catheterised at some stage of their hospital stay. The system for continuous drainage was not a completely closed one since there was an inadequately closed outlet from the urine bag. Urine bottles and bedpans were sources of the epidemic strain. Even with proper sterilisation urine bottles and bedpans can be reservoirs of Ps. aeruginosa (McLeod, 1958). These had been inadequately disinfected. Contamination of disinfectants with pseudomonads is well recognised (Burdon and Whitby, 1967). There seemed to be confusion about the concentration of the disinfectant solutions issued to the ward in which the outbreak occurred. Simple boiling and storing dry was instituted. The isolation of faecal organisms, including the epidemic strain of $P s$. aeruginosa, from the hands of attendant staff indicated that hand transmission may also have been important. The use of disinfectant was subsequently recommended for routine hand washing.

Although patients 1 and 3 appeared to have genuine urinary tract infections the outcome in each case was difficult to determine owing to the lack of routine follow-up urine specimens. It was clear that further specimens from patients $2,4,5$, and 6 were

Table 3 Incompatibility behaviour of pMG7. R151 determines resistance to carbenicillin, gentamicin, streptomycin, sulphonamides, and tobramycin but not to phages B3, D3, F116, or G101. Streptomycin was used to select for R151 transfer. Transconjugants were purified and tested for carbenicillin resistance to confirm $R 151$ transfer and for resistance to phages F116 and G101 as an indication that pMG7 was still present. pMG7 was perfectly stable (20/20 colonies tested) in absence of $R 151$ receipt

\begin{tabular}{llll}
\hline Donor & Recipient & Frequency of transfer & Transconjugants carrying each plasmid \\
\hline PU21 (R151) & PAO303 & $2 \times 10^{-2}$ & - \\
& PAO303 (pMG7) & $2 \times 10^{-6}$ & $3 / 17$ both present \\
\hline
\end{tabular}


Table 4 Antibiotic susceptibility (MIC) of mating strain and pMG7 transconjugant

\begin{tabular}{|c|c|c|c|c|c|c|c|c|}
\hline \multirow[t]{2}{*}{ Strain } & \multicolumn{8}{|c|}{ Antibiotic $(m g / l)$} \\
\hline & $A k$ & $B t$ & $G m$ & $K m$ & $\mathrm{Nm}$ & $P m$ & Sis & $T m$ \\
\hline $\begin{array}{l}\text { PU21 R- } \\
\text { PU21 pMG7 }\end{array}$ & $\begin{array}{l}10 \\
15\end{array}$ & $\begin{array}{l}50 \\
50\end{array}$ & $\begin{array}{r}5 \\
100\end{array}$ & $\begin{array}{r}200 \\
1000\end{array}$ & $\begin{array}{l}100 \\
100\end{array}$ & $\begin{array}{l}1000 \\
1000\end{array}$ & $100^{2 \cdot 5}$ & 50 \\
\hline
\end{tabular}

$\mathrm{Ak}=$ amikacin. $\mathrm{Bt}=$ butirosin. $\mathrm{Gm}=$ gentamicin. $\mathrm{Km}=$ kanamycin. $\mathrm{Nm}=$ neomycin. $\mathrm{Pm}=$ paromomycin. $\mathrm{Sis}=$ sisomicin. $\mathrm{Tm}=$ tobramycin.

Table 5 Substrate range of acetyltransferase from PU1 pMG7. Activities expressed relative to kanamycin A, which gave 2560 counts/min in the standard radioactive assay (Haas et al., 1976) with a background of 130 counts/min. Antibiotic abbreviations as in Table 4

\begin{tabular}{llllllllll}
\hline & \multicolumn{3}{l}{ Substrate } & & & & & \\
\cline { 2 - 9 } & $A k$ & $B t$ & $G m C_{13}$ & $K m A$ & $K m B$ & $K m C$ & $N m B$ & $P m$ & $T m$ \\
\hline Relative activity (\%) & 22 & 40 & 52 & 100 & 60 & 3 & 92 & 3 & 51 \\
\hline
\end{tabular}

required to confirm the presence of infection. But again the lack of adequate follow-up made the significance of the initial findings open to conjecture. Antibiotics seemed not to play a major role; only the first and third patients had gentamicin.

Although gentamicin resistance is no longer rare among clinical isolates of $P$ s. aeruginosa $\mathrm{R}$ plasmiddetermined resistance to gentamicin or tobramycin appears to be unusual. Nonetheless, outbreaks have occurred in burn units and urological wards in which $\mathbf{R}$ plasmid carriage has been demonstrated (Bryan et al., 1974; Jacoby, 1974a; Korfhagen et al., 1975). Bryan et al. (1972) first showed that Ps. aeruginosa rather than $E$. coli must be used as a recipient strain since plasmids in Pseudomonas may have a limited host range. An example from this outbreak is plasmid pMG7 that could be transmitted by conjugation between Pseudomonas strains but not to $E$. coli. The transfer frequency for Pseudomonas plasmids is quite variable. Some infect virtually all the cells of a recipient culture whereas others, like those described here, transfer at barely detectable frequency. There are also Pseudomonas plasmids that are non-conjugative or become nonconjugative after transfer (Iyobe et al., 1974; Korfhagen et al., 1976).

Resistant isolates from each of the cases in this outbreak were shown to carry plasmids determining resistance to gentamicin, kanamycin, sisomicin, sulphonamides, tobramycin, and mercuric salts. Each interfered with the propagation of the same subset of bacteriophages and each inhibited the fertility of plasmid RP1. Although transmissible from their strains of origin at comparable frequencies, seven of the eight plasmids were subsequently non- conjugative (Table 2). Possibly they are mobilised by another plasmid coexisting with them in the donor strains. Whether ultraviolet light resistance, which varied among the transconjugants, or the apparent $\mathrm{Tra}^{+}$character of plasmid pMG7 is due to a coexisting plasmid is currently being investigated. The evolution of an initially conjugative hospital $\mathbf{R}$ plasmid population to a non-conjugative one has recently been described by Korfhagen et al. (1976). Their R plasmids also originated in Ps. aeruginosa strains causing urinary tract colonisation.

Epidemiological investigation indicated that cross infection with the plasmid-carrying epidemic strain was the major mechanism of spread. However, transmission of an $\mathbf{R}$ plasmid apparently occurred from the epidemic strain to other organisms since Ps. aeruginosa isolate No. 1996, differing in serological, phage, and pyocin type from the epidemic strain, also carried a plasmid with properties similar to those found in the epidemic strain (Table 2).

Plasmids of Ps. aeruginosa may be classified by several criteria (Jacoby, 1977). One of the most useful is incompatibility, manifested by the inability of two plasmids belonging to the same incompatibility group to coexist stably in the same host cell (Novick et al., 1976). At least 10 incompabitility groups have been described for Pseudomonas plasmids (Jacoby, 1977). The prototype of incompatibility group P-1 was isolated in the United Kingdom (Datta et al., 1971). Until now plasmids of other incompatibility groups have not been found there in natural isolates. Plasmids from this outbreak belong to incompatibility group P-3. P-3 plasmids have previously been found in resistant $P$ s. aeruginosa strains in Paris, Chicago, and Athens (Witchitz and 
Chabbert, 1971; Bryan, et al., 1974; Kontomichalou et al., 1976). Some are transmissible between Pseudomonas and $E$. coli, where they belong to incompatibility group C or 6 (Chabbert et al., 1972; Datta and Hedges, 1972). Our results suggest that such plasmids may evolve in Ps. aeruginosa so that transmissibility to $E$. coli and even to other Pseudomonas strains is lost.

Cell-free extracts of a strain carrying pMG7 contained an active aminoglycoside acetylating enzyme. Activity against kanamycin A but not kanamycin $\mathrm{C}$ or paromomycin suggests the presence of a $6^{\prime}-N$-acetylating enzyme (Haas et al., 1976). $6^{\prime}-N$-acetyltransferases with a variety of substrate ranges are known(Jacoby, 1974b; Kawabe et al., 1975a; Kawabe et al., 1975b). Although the transferase determined by pMG7 acetylates neomycin B, amikacin, and butirosin (Table 5) strains carrying pMG7 lack enhanced resistance to these aminoglycosides (Table 4). Factors other than antibiotic modification must play an important role in $\mathrm{R}$ plasmid determined aminoglycoside resistance (Dowding and Davies, 1975; Haas et al., 1976).

We thank Dr M. T. Parker, Cross-Infection Reference Laboratory, Central Public Health Laboratory, Colindale, London, for serological and bacteriophage typing and Barbara Hoffman and Julian Davies for assays of aminoglycoside inactivation. We also thank the consultants and staff of the Federated Dublin Voluntary Hospitals and the Central Microbiology Laboratory for their co-operation. G. A. J. was partly supported by a grant from the National Science Foundation. F. R. F. was supported by a grant from the Laboratory Medicine Development Fund.

Requests for reprints should be addressed to Conor T. Keane, Central Microbiology Laboratory, Adelaide Hospital, Dublin 8.

\section{References}

Barnham, M., Maddocks, A. C., and Gaya, H. (1975). Pseudomonas aeruginosa resistant to gentamicin (Letter). Lancet, 1, 576.

Brown, V. I. and Lowbury, E. J. L. (1965). Use of an improved cetrimide agar medium and other culture methods for Pseudomonas aeruginosa. Journal of Clinical Pathology, 18, 752-756.

Bruun, J. N., Bøe, J., and Solberg, C. O. (1968). Disinfection of the hands of ward personnel. Acta Medica Scandinavica, 184, 417-423.

Bryan, L. E., Semaka, S. D., Van Den Elzen, H. M., Kinnear, J. E., and Whitehouse, R. L. S. (1973). Characteristics of R931 and other Pseudomonas aeruginosa R factors. Antimicrobial Agents and Chemotherapy, 3, 625-637.
Bryan, L. E., Shahrabadi, M. S., and Van Den Elzen, H. M. (1974). Gentamicin resistance in Pseudomonas aeruginosa: R-factor-mediated resistance. Antimicrobial Agents and Chemotherapy, 6, 191-199.

Bryan, L. E., Van Den Elzen, H. M., and Tseng, J. T. (1972). Transferable drug resistance in Pseudomonas aeruginosa. Antimicrobial Agents and Chemotherapy, 1, 22-29.

Burdon, D. W. and Whitby, J. L. (1967). Contamination of hospital disinfectants with Pseudomonas species. British Medical Journal, 2, 153-155.

Chabbert, Y. A., Scavizzi, M. R., Witchitz, J. L., Gerbaud, G. R., and Bouanchaud, D. H. (1972). Incompatibility groups and the classification of $\mathrm{fi}^{-}$ resistance factors. Journal of Bacteriology, 112, 666-675.

Datta, N. and Hedges, R. W. (1972). R factors identified in Paris, some conferring gentamicin resistance, constitute a new compatibility group. Annales de l'Institut Pasteur (Paris), 123, 849-852.

Datta, N., Hedges, R. W., Shaw, E. J., Sykes, R. B., and Richmond, M. H. (1971). Properties of an R factor from Pseudomonas aeruginosa. Journal of Bacteriology, 108, $1244-1249$.

Dowding, J. and Davies, J. (1975). Mechanisms and origins of plasmid-determined antibiotic resistance. In Microbiology-1974, edited by D. Schlessinger, pp. 179-186. American Society for Microbiology, Washington, D.C.

Eykyn, S. and Phillips, I. (1975). Gentamicin resistant Pseudomonas aeruginosa (Letter). Lancet, 1, 861-862.

Govan, J. R. W. and Gillies, R. R. (1969). Further studies in the pyocine typing of Pseudomonas pyocyanea. Journal of Medical Microbiology, 2, 17-25.

Haas, M., Biddlecome, S., Davies, J., Luce, C. E., and Daniels, P. J. L. (1976). Enzymatic modification of aminoglycoside antibiotics; a new $6^{\prime}-\mathrm{N}$-acetylating enzyme from a Pseudomonas aeruginosa isolate. Antimicrobial Agents and Chemotherapy, 9, 945-950.

Holloway, B. W. (1965). Variations in restriction and modification of bacteriophage following increase of growth temperature of Pseudomonas aeruginosa. Virology, 25, 634-642.

Iyobe, S., Hasuda, K., Fuse, A., and Mitsuhashi, S. (1974) Demonstration of $\mathbf{R}$ factors from Pseudomonas aeruginosa. Antimicrobial Agents and Chemotherapy, 5 , 547-552.

Jacoby, G. A. (1974a). Properties of R plasmids determining gentamicin resistance by acetylation in Pseudomonas aeruginosa. Antimicrobial Agents and Chemotherapy, 6, 239-252.

Jacoby, G. A. (1974b). Properties of an R plasmid in Pseudomonas aeruginosa producing amikacin (BE-K8), butirosin, kanamycin, tobramycin, and sisomicin resistance. Antimicrobial Agents and Chemotherapy, 6, 807-810.

Jacoby, G. A. (1977). Classification of plasmids in Pseudomonas aeruginosa. In Microbiology - 1977, edited by D. Schlessinger. American Society for Microbiology, Washington, D.C. (In press.)

Kawabe, H., Kondo, S., Umezawa, H., and Mitsuhashi, S. (1975a). R factor-mediated aminoglycoside anti- 
biotic resistance in Pseudomonas aeruginosa; a new aminoglycoside 6'-N-acetyltransferase. Antimicrobial Agents and Chemotherapy, 7, 494-499.

Kawabe, H., Naito, T., and Mitsuhashi, S. (1975b). Acetylation of amikacin, a new semisynthetic antibiotic, by Pseudomonas aeruginosa carrying an $\mathbf{R}$ factor. Antimicrobial Agents and Chemotherapy, 7, 50-54.

Kontomichalou, P., Papachristou, E., and Angelatou, F. (1976). Multiresistant plasmids from Pseudomonas aeruginosa highly resistant to either or both gentamicin and carbenicillin. Antimicrobial Agents and Chemotherapy, 9, 866-873.

Korfhagen, T. R., Ferrel, J. A., Menefee, C. L., and Loper, J. C. (1976). Resistance plasmids of Pseudomonas aeruginosa: change from conjugative to nonconjugative in a hospital population. Antimicrobial Agents and Chemotherapy, 9, 810-816.

Korfhagen, T. R., Loper, J. C., and Ferrel, J. A. (1975). Pseudomonas aeruginosa $\mathrm{R}$ factors determining gentamicin plus carbenicillin resistance from patients with urinary tract colonisations. Antimicrobial Agents and Chemotherapy, 7, 64-68.

McLeod, J. W. (1958). The hospital urine bottle and bedpan as reservoirs of infection by Pseudomonas pyocyanea. Lancet, 1, 394-397.

Novick, R. P., Clowes, R. C., Cohen, S. N., Curtiss, R.
III, Datta, N., and Falkow, S. (1976). Uniform nomenclature for bacterial plasmids: a proposal. Bacteriological Reviews, 40, 168-189.

Olsen, R. H. and Hansen, J. (1976). Evolution and utility of a Pseudomonas aeruginosa drug resistance factor. Journal of Bacteriology, 125, 837-844.

Phillips, I. (1969). Identification of Pseudomonas aeruginosa in the clinical laboratory. Journal of Medical Microbiology, 2, 9-16.

Seal, D. V. and Strangeways, J. E. M. (1975). Resistant pseudomonads in a neurosurgical unit (Letter). Lancet, 1, 48-49.

Shooter, R. A., Walker, K. A., Williams, V. R., Horgan, G. M., Parker, M. T., Asheshov, E. H., and Bullimore, J. F. (1966). Faecal carriage of Pseudomonas aeruginosa in hospital patients-possible spread from patient to patient. Lancet, 2, 1331-1334.

Smith, R. F. and Dayton, S. L. (1972). Use of acetamide broth in the isolation of Pseudomonas aeruginosa from rectal swabs. Applied Microbiology, 24, 143-145.

Stanisich,V. A. (1974). The properties and host range of male-specific bacteriophages of Pseudomonas aeruginosa. Journal of General Microbiology, 84, 332-342.

Witchitz, J. L. and Chabbert, Y. A. (1971). Résistance transférable à la gentamicine. 1. Expression du caractère de résistance. Annales de l'Institut Pasteur (Paris), 121, 733-742. 